\title{
Chemometric Analysis of an Sanitary Landfill Leachate
}

\author{
Ana M. C. Grisa, Cíntia Paese, Oclide José Dotto, Ronaldo Nicola, Mara Zeni \\ Universidade de Caxias do Sul, Caxias do Sul, Brazil \\ Email:mzandrad@terra.com.br
}

Received July 22, 2011; revised August 29, 2011; accepted November 5, 2011

\begin{abstract}
This paper presents a study on the biotic/abiotic conditions of the São Giácomo sanitary landfill, located near the city of Caxias do Sul, Brazil, through statistical analysis of fourteen physic-chemical data sets for the leachate, produced in the garbage dump site over a long period of years. Different chemometric methods are used in the statistical analysis. For example, the correlations between the variables, related to the degraded organic matter and biological activity, are determined by means of multivariate methods. The results highlight that BOD, COD, VTS, FTS and TS give information on the anaerobic degradation of the organic matter contained in the cells, and suggest that the greater the contribution of the variables with positive weights in PC1 the greater the level of organic matter degradation. The variables TN, Amon Nit. and alkalinity are related to the biological activity and determine the potency of the variables in relation to time. The greater the contribution of the variables related to organic degradation the greater the values in PC2 and the lesser the potency of these variables, whose influence is greater in the second stage of anaerobic degradation. The variables of PC2 is important plans of the contamination of the leached in the bodies hídrics.
\end{abstract}

Keywords: Landfill Leachate; Physico-Chemical Variables; Chemometric Method; Principal Components Analysis

\section{Introduction}

A sanitary landfill is predominantly an anaerobic biological system, in which the treatment of the deposited domestic solid residues occurs through the interaction of different microbial species. The development of the biosistem allows the conversion of the organic matter into methane gas and percolated liquids. The percolated/lixiviated liquids, commonly refered to as leachate, are the result of the enzymatic action of the microorganisms of the system and the resulting products of biodegradation [1]. The microbial activity in each stage of the solid residue stabilization process gives typical character ristics to the leachate. The variation in the leachate quality is generally attributed to a myriad of interacting factors such as type and depth of the solid waste, age of fill, rate of water flow and the interaction of the leachate with its environment $[2,3]$.

Leached him it is the main source poluidora of the underground waters and surfaces. The impact produced for the leached on the environment it is directly related with its phase of decomposition [4].

The stabilization degree, organic residue mineralizetion, organic matter distribution and the intervention of diverse groups of bacteria and fungi that act simultaneously influence, with regard to the leachate composition, the anaerobic digestion. In the anaerobic degradation, nitrogen is important for determining the nutrient sufficiency of the conditions (aerobic and anaerobic) at each stage of the stabilization $[5,6]$.

Environmental concerns regarding methanogenic-state landfill leachates, characterized by low organic carbon concentration, high ammonia-N levels, and a large spectrum of metals. The slow leaching of nitrogen from solid waste in landfills, resulting in high concentrations of ammonia in the landfill leachate, may last for several decades [7].

The main potential effects of the release of the leached in bodies hidric associated to the decrease of the concentation of the dissolved oxygen, to the toxic caused by the $\mathrm{NH}_{3}$ and the eutrophication due to the high concentrations of $\mathrm{N}_{2}$ [8].

The area named Vazadouro de São Giácomo, in the peripheral region of Caxias do Sul, RS, Brazil, on the banks of the Tega River, received in a disorderly form, for a period 1988 to 1990, the urban solid residues produced in the city, causing the environmental degradation of an area of approximately 1.4 hectares (Figure 1).

The remediation project for the area degraded by solid waste was prioritized aiming to minimize the generation of percolated liquids and to carry out environment monitoring. The arrangement of the solid waste in layers or cells was executed according to the NBR 8418/1984 and the NBR $8419 / 1984$ norms, and the resulting system is monitored monthly.

The most easily found post-consumption thermoplastic 


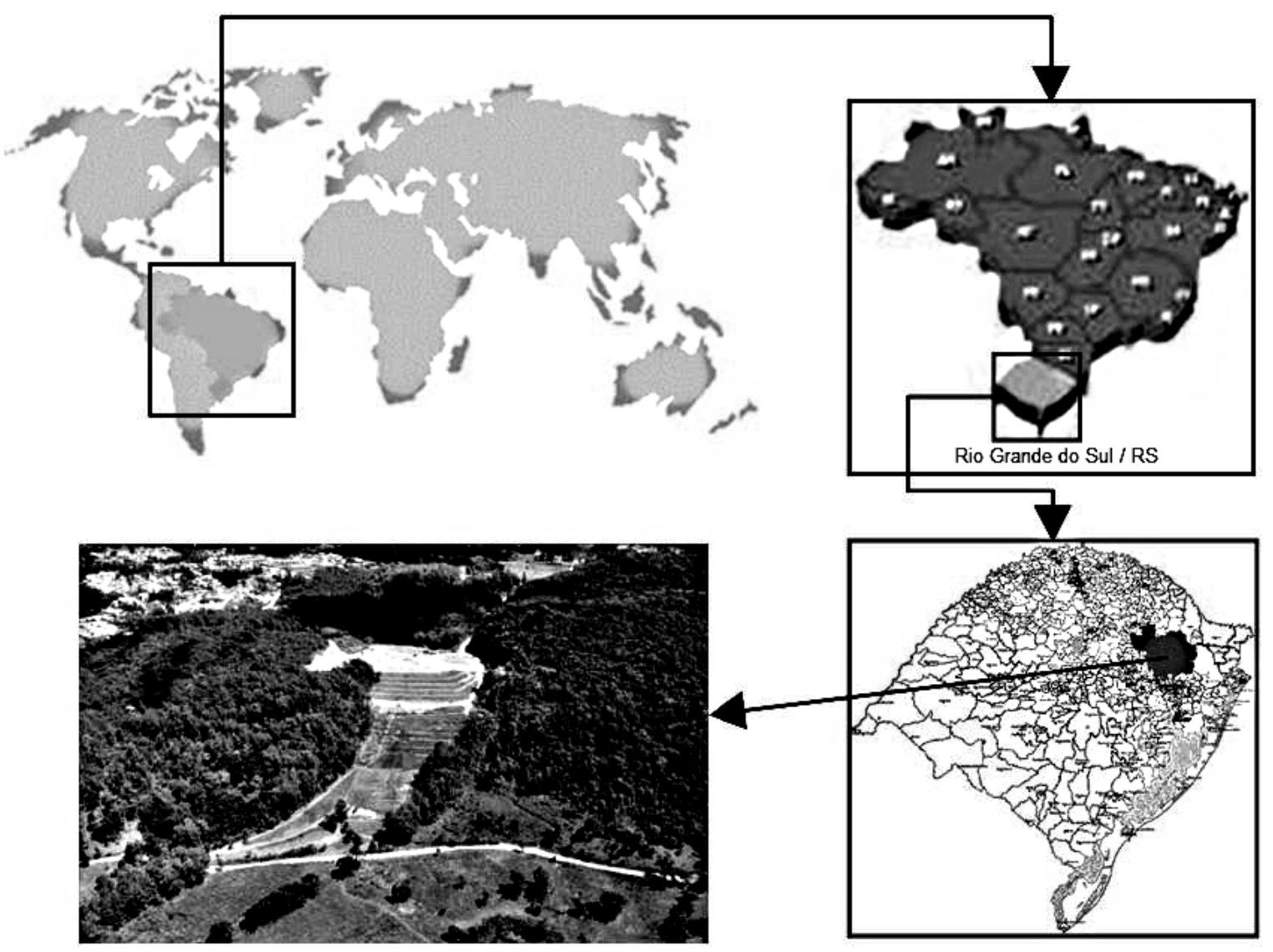

Figure 1. The sanitary landfill São Giácomo near the city Caxias do Sul, RS, Brazil.

polymers, defined as commodities, are: low density polyethylene (LDPE), high density polyethylene (HDPE), polypropylene (PP), polyvinyl chloride (PVC) and polystyrene (PS). It has been estimated that in Europe the consumption of thermoplastics is $80 \mathrm{~kg} / \mathrm{habitant} /$ year and in Brazil it is around $23 \mathrm{~kg} /$ habitant/year [9]. Since these polymers have a high resistance to degradation, large volumes are discarded to garbage dump sites and industrial waste sites.

In this study fourteen physic-chemical variables of the leachate are analyzed along with the factors which influence the organic matter degradation at the São Giácomo sanitary landfill, consisting of seven refuse cells of different ages, by means of principal components analysis (PCA). In this work the objective was to study the degradation of organic substances and the biological activity of the physic-chemical leachate variables in the cells of different ages from the sanitary landfill.

Chemometric analysis method and principal component analysis were used for interpretation and to indicate associations between the variables.

Later on, in another work, these factors will be considered in relation to the biodegradation or oxidative degradation of the organic matter and the buried polymers in the landfill.

\section{Experimental Part}

\subsection{Physico-Chemical Parameters}

The data set for fourteen physico-chemical parameters was compiled over ten years by the Instituto de Saneamento Ambiental (Environmental Health Institute of the University of Caxias do Sul) and by the Companhia do Desenvolvimento (Development Company of Caxias do Sul) (CODECA) [10], and relates to leachate flowing from the São Giácomo sanitary landfill. This landfill comprises seven cells of different ages. The cells are denoted as follows (the numbers inside parentheses indicate the age in months): C1 (136), C3 (115), C4 (94), C5 (54), C7 (43), C8 (27) and C9 (20).

The samples were analysed with respect to fourteen parameters: $\mathrm{pH}$, alkalinity, total solids (TS) , volatile total solids (VTS), fixed total solids (FTS), chemical oxygen demand (COD), biochemical oxygen demand (BOD) , total nitrogen (TN.), amoniac nitrogen (Amon Nit.), cadmium $(\mathrm{Cd})$, copper $(\mathrm{Cu})$, iron $(\mathrm{Fe})$, manganese $(\mathrm{Mn})$ and zinc ( $\mathrm{Zn})$. The chemical components to be analyzed were chosen on a list of priority degradation and bio- 
logical activity in the organic matter.

The variables collected at the sanitary landfill (Figure 1) were correlated and analyzed by chemometric methods using multivariate statistics in the treatment and chemical analysis in order to extract the maximum chemical information. The chemometric methods were applied through the classification and comparison of different samples [11] by determining correlations between the degradation of organic substances and the biological activity.

\subsection{Multivariate Analysis}

The physic-chemical variables of the leachate were investigated by different chemiometric methods: basic statistical methods for the determination of mean and values, standard deviations, minimum and maximum, and the principal components analysis method for advanced information, everything through the software Statistical Product and Service Solution (SPSS).

The problems originated from some missing values were minimized using the procedure "exclude marry listwise" available in SPSS. The variables were standardized to remove the influence of the measures units and the values magnitudes.

Before using PCA, mathematical manipulation of the data set was carried out, describing, investigating and comparing the variables in the set, aiming at predicting models through the multivariate analysis (median, mean values, standard deviations, etc.).

The multivariate analysis was performed through PCA [12-14], which is an efficient way to suppress redundant information on the multidimensional initial data and to obtain the relevant non-correlated information. This means that the covariance matrix of the variables $\mathbf{X}_{1}, \mathbf{X}_{2}, \cdots$, $\mathbf{X}_{\mathrm{N}}$ containing the data is diagonal or quasi diagonal.

Initially we have a matrix $\left[\mathbf{X}_{1}, \mathbf{X}_{2} \cdots \mathbf{X}_{\mathrm{N}}\right]$ of the data which is transformed to the centered form (mean-deviation form), or to another convenient form for analysis. Let us assume that the example matrix shown is already in such a form. The aim of PCA is to find an orthogonal matrix $\mathbf{P}=\left[\begin{array}{llll}\mathbf{u}_{1} & \mathbf{u}_{2} & \cdots & \mathbf{u}_{\mathbf{p}}\end{array}\right]$, that is, a matrix $\mathbf{P}$ such that $\mathbf{P}^{\mathbf{t}} \mathbf{P}$ $=\mathbf{I}$, which defines a change of variable $\mathbf{X}=\mathbf{P Y}$; with another notation,

$$
\left[\begin{array}{c}
x_{1} \\
x_{2} \\
\vdots \\
x_{p}
\end{array}\right]=\left[\begin{array}{llll}
\mathbf{u}_{1} & \mathbf{u}_{2} & \cdots & \mathbf{u}_{\mathbf{p}}
\end{array}\right]\left[\begin{array}{c}
y_{1} \\
y_{2} \\
\vdots \\
y_{p}
\end{array}\right],
$$

where the new coordinates $y_{1}, y_{2}, \cdots, y_{3}$ are uncorrelated and are displayed in descending order of variance. The unitary vectors $\mathbf{u}_{1}, \mathbf{u}_{2}, \cdots, \mathbf{u}_{\mathbf{p}}$, arranged in ascending order of importance, are named Principal Components (PCs) of the data (observations matrix). These PCs are described in terms of eigenvalues of some matrix.

The first principal component (PC1) $\mathbf{u}_{1}$ determines a new variable $y_{1}$ in the following way. Let $c_{1}, c_{2}, \cdots, c_{p}$ be the $\mathbf{u}_{1}$ coordinates. Since the transposed vector $\mathbf{u}_{1}^{\mathrm{t}}$ is the first line of $\mathbf{P}^{\mathrm{t}}$, the equation $\mathbf{Y}=\mathbf{P}^{t} \mathbf{X}$ show that,

$$
y_{1}=\mathbf{u}_{1}^{\mathrm{t}} \mathbf{X}=c_{1} x_{1}+c_{2} x_{2}+\cdots+c_{p} x_{p}
$$

We see that $y_{1}$ is a linear combination of the original variables $x_{1}, x_{2}, \cdots, x_{p}$, that have the coordinates of $\mathbf{u}_{1}$ as its coefficients. In the same way, $\mathbf{u}_{2}$ determines a variable $\boldsymbol{y}_{2}$, ecc.

So, by means of the PCA we obtain the least number of uncorrelated variables, which are a linear combination of the initial ones, allowing the description of the structure and the interconnections of the original variables of the phenomenon being studied, with base on the PCs obtained. The results of the PCA can be visualized by graphs of the scores which allow an estimation of the influence of each variable of each sample $[15,16]$.

The representation and analysis of weights and scores graphs obtained from the relations between the physicchemical variables of each sanitary landfill cell, per lifetime, determines the probability distribution. Through the interpretation of the resulting data, correlating these data and that for the other cells of the landfill and using PCA, the factors which account for the maximum variance in all observed variables are obtained. The choice of PCs to describe the data was made considering the percentage of the variance they describe and the residual variance.

\section{Results and Discussion}

After determining the mean value and standard deviation, the correlation was studied for all measured varaibles. The data were autoscaled (mean equal zero and variance equal 1). The application of the main components is to reduce the dimensions of the original variables and for the extraction of the main components it is selected the components main through of the scree plots.

The sedimentation graphs (eigenvalue relations and component numbers) obtained from the PCA indicate the number of PCs that were used for each cell. The adopted approach refers the use of the eigenvalues that they possess larger capacity to explain the larger total variability. The percentages of variances in resulting eigenvectores (PCs) [16-18].

An analysis of the correlation matrix allowed to uncover strong associations between some variables PCA showed the existence of the two a at four a significant PCs.

It is reasonable to expect that two to four main components were enough to describe the original variables of each cell of the sanitary landfill. In fact, according Table 1, two PCs for C5 and C7 are sufficient to describe the data, since they contain $79.93 \%$ and $80.52 \%$, respectively, 
of the original results, while, for the cell C1, four PCs contain $77.75 \%$ of the variability of the data. The results for cell C1 demand four PCs due to the disorderly arrangement of the solid waste in the landfill, which requires a larger number of representative variables. For cells C3, C4, C8 and C9 three PCs are needed to describe the original data, since they contain $69.20 \%$, 81.55\%, $88.911 \%$ and $85.27 \%$, respectively, of the original results of the data.

It can be observed that for the more recent cells the variance percentage of the original data is greater, due to the high level of organic matter degradation (major activity). The other cells show signs of stabilization, since their degradation stages occur under neutral and alkaline $\mathrm{pH}$ conditions.

In Table 1, PCi, $\mathrm{i}=1,2,3,4$, indicates the $\mathrm{i}^{\text {th }}$ principal component. As it can be seen in the table, cells C1 (39.95\%), C4 (53.52\%), C5 (50.11\%), C7 (53.50\%) and C8 (54.17\%) give the variables COD, BOD, VTS, TS, FTS as corresponding to first principal component (PC1). Except for C3 and C9, the cells have as PC1 the correspondent variables BOD, COD, VTS, FTS and TS, indicative of anaerobic degradation of the organic matter in the cells.

The second principal component (PC2), Table 1, for cells C1, C3, C4, C5, C7, C8 and C9, are associated to the variables TN., Nit. Amon. and alkalinity, that control the acidity in the development of the bacterial biological activity.

Due to the low percentage of metals, the analysis for
PC3 was not performed in this study. Even so, the presence of metals should be considered in the landfill, since they are responsible for movement and complexation in the formation of acids, and complexation and precipitation of the metallic species during methanogenic fermentation.

The PCA results are visualized in graphs that identify clusters of physico-chemical variables values. The weights graphs (Figures 2(a) and 3(a)) contain important information that allows us to describe the variation in the original data, and the scores graphs (Figures 2(b) and 3(b)) exhibit information about the age of the cells, making similarities, clusters and differences visible, based on the used variables.

From the behavior of the physico-chemical variables in terms of lifetime (Figures 2(a) and 3(a)) it can be concluded that the greater the contribution of the variables with positive weights in PC1 the greater the degradation of the organic matter (variables in PC1). The negative values for the weights in PC2 demonstrate that the variation in the values for the physico-chemical variables influences the second stage of anaerobic degradation.

On considering cells C5 and C7 (Figures 2(a) and (b)), with respective ages of 54 and 42 months, in the scores graph (Figures 2(b)) for PC1, the group on the left side decreases over time, due to the degradation of organic matter consumed in the landfill.

PC2 is related to the biological activity which increases over time. The variables (more active variables) in PC2, located on the lower part of the scores graph (Fig-

Table 1. Percentage of variance and PCs (physic-chemical parameters) for the São Giácomo sanitary landfill.

\begin{tabular}{|c|c|c|c|}
\hline Cell & CPs & $\%$ Variance & CPs variables \\
\hline \multirow[t]{4}{*}{ C1 } & PC1 & 39.954 & BOD, COD, VTS, FTS, TS, alcalinity, Zn \\
\hline & PC2 & 16.097 & BOD, FTS, alkalinity, Amon. Nit., Total Nit , pH, Cd \\
\hline & PC3 & 13.456 & $\mathrm{Cu}, \mathrm{Mn},-\mathrm{pH}$ \\
\hline & PC4 & 8.249 & $\mathrm{Cd}, \mathrm{Mn}, \mathrm{Fe}$ \\
\hline \multirow[t]{3}{*}{ C3 } & PC1 & 33.54 & FTS, TS, alkalinity, Amon. Nit., Total Nit., pH \\
\hline & PC2 & 23.037 & BOD, COD, VTS, TS, -Amon.Nit., Cu, Zn, -Cd \\
\hline & PC3 & 12.627 & Total Nit., -Cu, -Zn, Mn, Fe \\
\hline \multirow[t]{3}{*}{$\mathrm{C} 4$} & PC1 & 53.527 & BOD, COD, FTS, VTS, ST, Cd, Zn, Cu, -pH, Nit. Amon. \\
\hline & PC2 & 20.584 & alkalinity, -Amon. Nit., Total Nit., -Cd \\
\hline & PC3 & 7.446 & $\mathrm{Fe}, \mathrm{Mn}$ \\
\hline \multirow[t]{2}{*}{$\mathrm{C} 5$} & PC1 & 50.113 & BOD, COD, FTS, STV, ST, Fe, Zn, Mn, -pH \\
\hline & PC2 & 29.283 & FTS, alkalinity, Amon. Nit., Total Nit., Cu, -Cd \\
\hline \multirow[t]{2}{*}{ C7 } & PC1 & 53.507 & BOD, CDO, FTS, VTS, TS, Mn, Zn, Cu, Fe, -pH \\
\hline & PC2 & 27.018 & FTS, alkalinity, Amon. Nit., Total Nit., -Fe, pH \\
\hline \multirow[t]{3}{*}{$\mathrm{C} 8$} & PC1 & 54.172 & BDO, COD, FTS, VTS, ST, Fe, Mn, Zn, Cu, -pH \\
\hline & PC2 & 26.938 & FTS, alkalinity, Amon. Nit., Total Nit., pH \\
\hline & PC3 & 7.801 & Zn, Cd \\
\hline \multirow[t]{3}{*}{ C9 } & PC1 & 54.381 & $\begin{array}{l}\text { BOD, COD, -alkalinity, -Total Nit., Fe, Mn, -pH } \\
\text { FTS, VTS, -Amon. Nit. Amon., Zn }\end{array}$ \\
\hline & PC2 & 21.511 & VTS, -FTS, -Amon.Nit., Zn \\
\hline & PC3 & 9.378 & $\mathrm{Cu}, \mathrm{Cd},-\mathrm{Zn}$ \\
\hline \multirow[t]{2}{*}{ C10 } & PC1 & 79.838 & BOD, COD, FTS, VTS, ST, Amon. Nit., Total Nit., Fe, Mn, alkalinity, Zn \\
\hline & PC2 & 18.877 & FTS, Amon. Nit., Total Nit., -Zn, pH \\
\hline
\end{tabular}



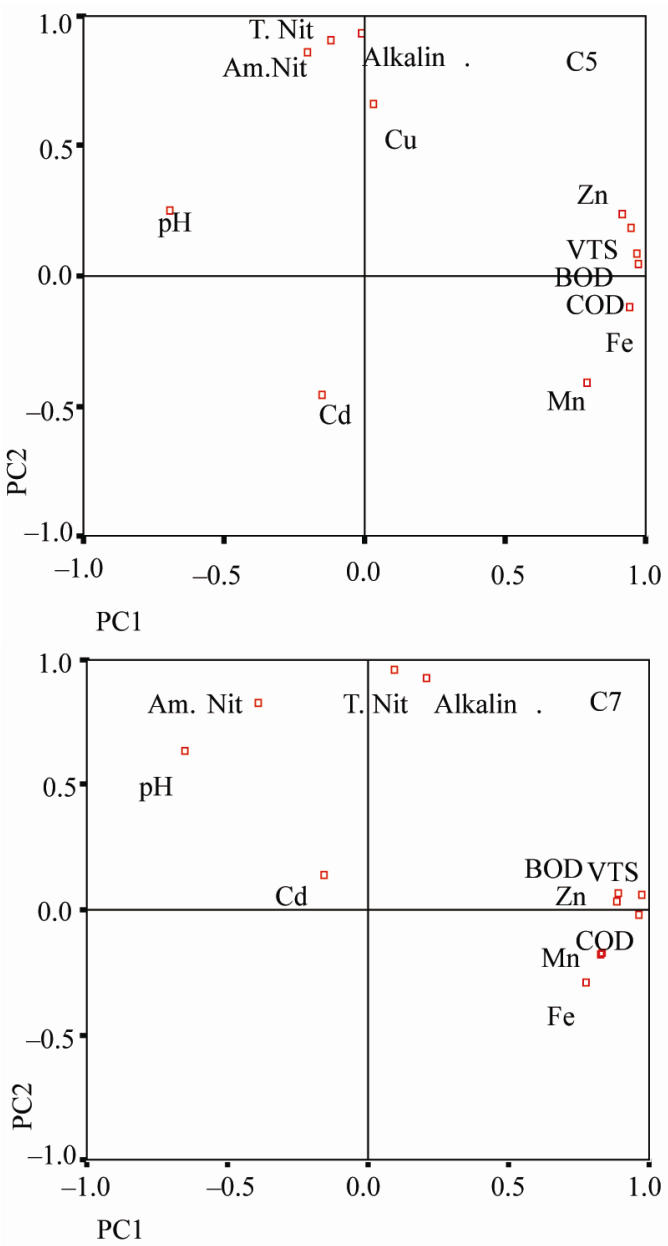

(a)
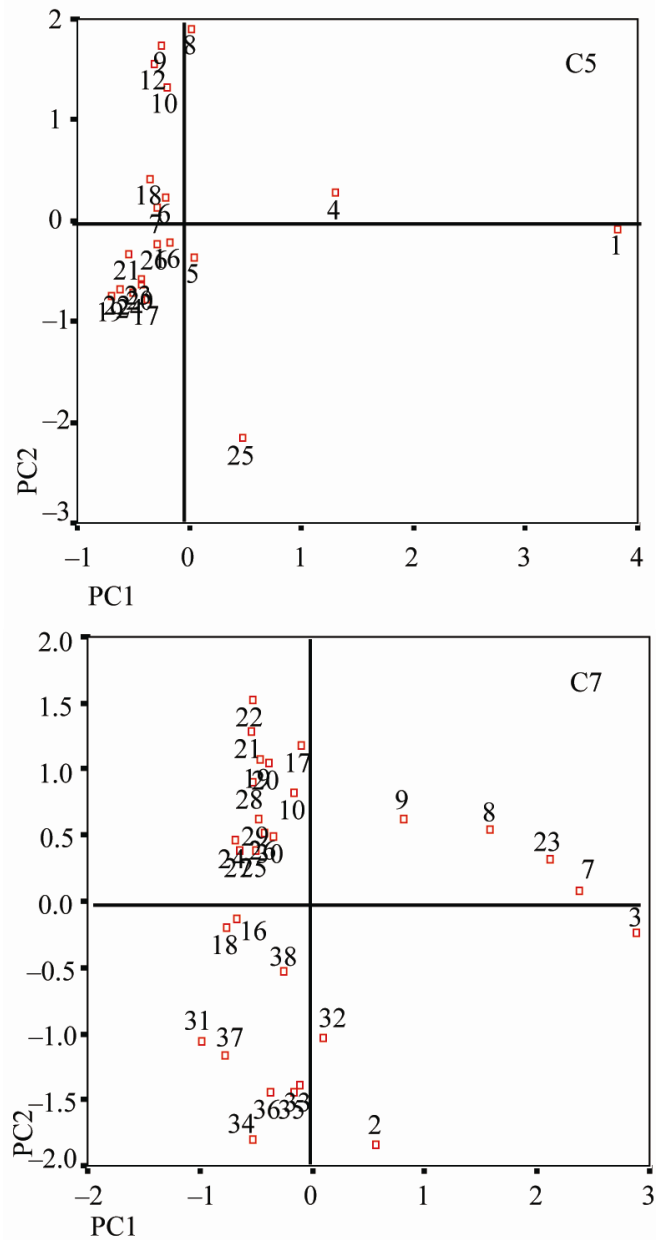

(b)

Figure 2. Graph of (a) weight (b) scores for cells C5 and C7.

ures 2(b)), are more meaningful (i.e. potent) in relation to the biological activity, while the less potent ones have positive scores.

The organic matter degradation is aided by the presence of nitrogen, which is important in the determination of the nutrient sufficiency of the aerobic and anaerobic conditions during each stabilization phase.

For cells C3, C4, C8 and C9, with 115, 94, 27 and 20 months of age, respectively, three PCs were considered and for cell C1, with 136 months of age, four PC's were considered.

In order to visualize the weights and scores of cells $\mathrm{C} 1$, C3, C4, C8 and C9, aiming a better interpretation, twodimensional graphs of PC1 versus PC2 and PC1 versus PC3 (Figures 3(a) and (b)) were constructed. The interprettation of the two-dimensional scores graph (Figure 3(b)) allows a prediction, based on PC2, of the most significant time values in relation to the biological activeity on the organic matter (potency).

Since cell C1 has a disorderly arrangement of residues, PC2 (Figure 3(b)) has higher values in the scores graph for the numeric variables at the upper part and less potent ones in the lower part. It may therefore be concluded that degradation of the organic matter takes place in the final months and that, for the variables with numeric values from 40 to 85 , the biological activity reflects the more potent variables. In this cell, the degradation of the organic matter occurs more intensely over time, but one can note a less potent biological activity.

Considering cells C4 and C8, for PC2, the most potent variables are located on the lower part of the scores graph (Figure 3(b)), while the less potent ones are on the upper part. These positions in the weights graph (Figures 3(a)), PC1 versus PC2, indicate that the greater the contribution of the variables related to organic degradation the greater the score values in PC2, and the lesser the potency of these variables.

From an analysis of the newest cell C9, it can be seen that its potent variables are on the lower and the upper parts of the graph, indicating that the degradation of organic matter and the biological activity occur simultaneously. 

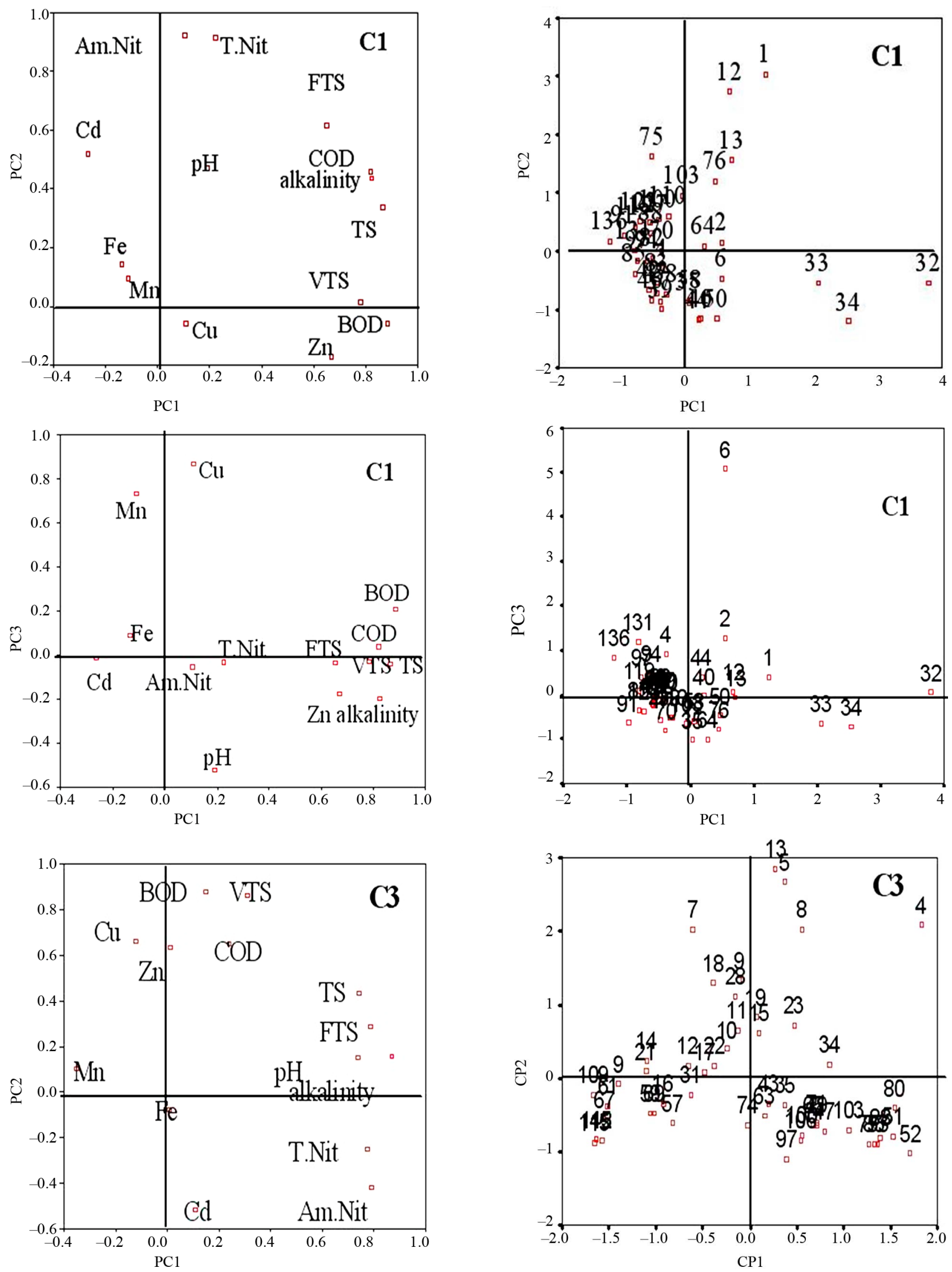

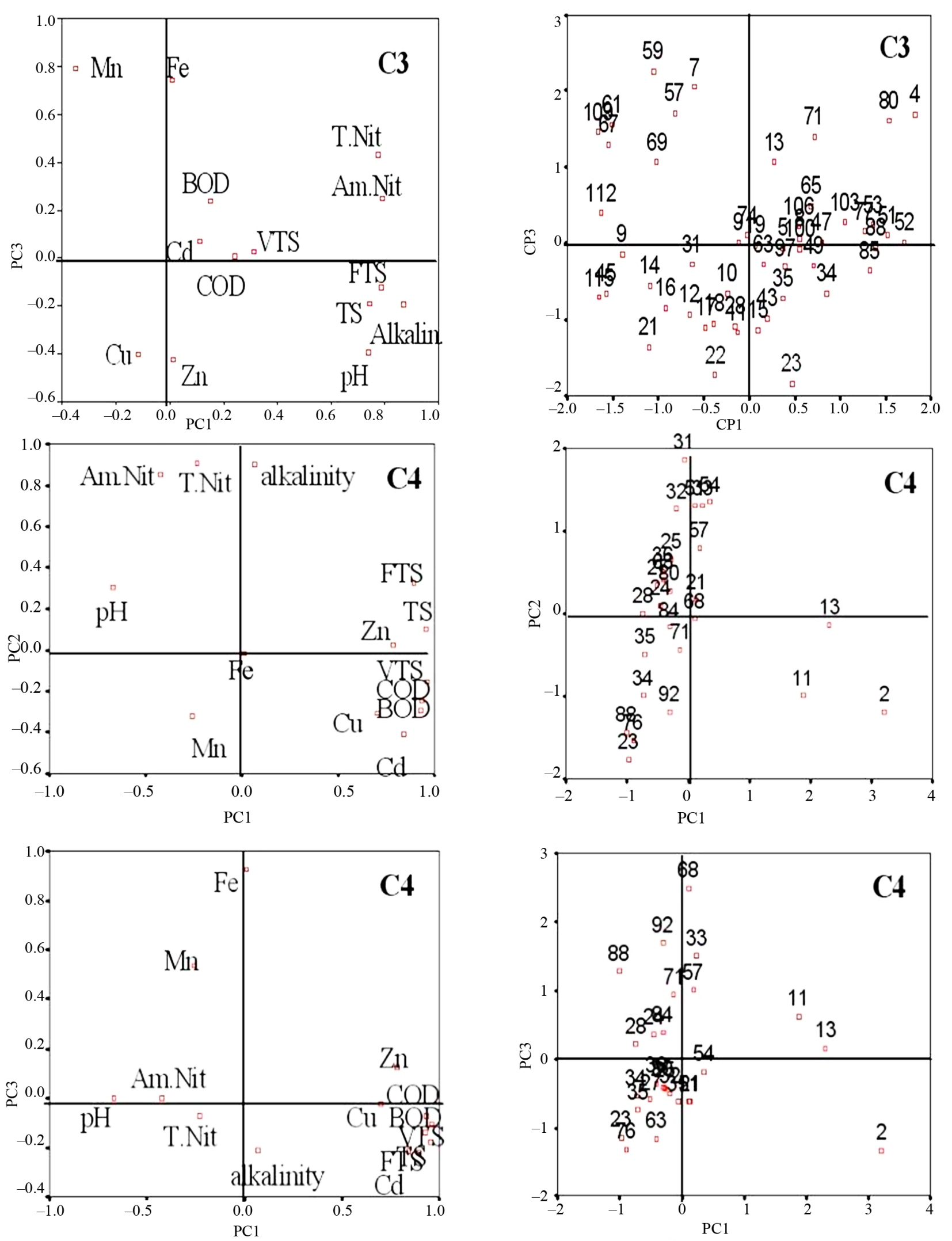

(a)

(b)

Figure 3. Physico-chemical parameters PC1 versus PC2 and PC1versus PC3 (a) weight (b) scores for cells C1, C3 and C4. 
An analysis of the biodegradability of the organic matter is of fundamental importance in the study of the abiotic factors that act on the sanitary landfill ecosystem. Such an analysis can reveal the presence of anaerobic microbial activity, considering that the leachate of cells C1, C3 and C4 has predominantly methanogenic characteristics (in $70 \%$ of the cases the BOD/COD ratio was below $0.4)$.

The newest cells C5, C6, C7 and C9 are in an unstable methanogenic phase (BOD/COD > 0.4), and an overlap of the stabilization stages can be observed during the degradation process, due to the heterogeneity of the material deposited in the landfill.

\section{Conclusions}

The physic-chemical and biological processes in a sanitary landfill, which lead to the degradation of the organic components of the dumped mass of solid waste, can be monitored through the collection of data that served to indicate the decomposition state of the dumped mass and the transformations that go on at the site. The sanitary landfill can be considered as a biological reactor, where there are suitable conditions for the growth of the bacteria that are responsible for biodegradation.

The chemometric analysis of the leachate data coming from São Giácomo sanitary landfill in Caxias do Sul, according the principal components analysis of fourteen physico-chemical parameters obtained from the leachate relating to seven studied cells, showed that two to four PCs are enough to describe the original data and identified the physic-chemical parameters related to the anaerobic digestion (enzymatic action) in terms of the leachate composition [19,20].

It could be observed that for the newest cells, the percentage of variance in the original data is greater than for others, due to the high concentration of organic matter undergoing degradation (more activity), the older cells showing signs of stabilization.

The PCA results highlight, in PC1 (BOD and COD, VTS, FTS and TS), variables that give information on the anaerobic degradation of the organic matter contained in the cells, and suggest that the greater the contribution of the variables with positive weights in PC1 the greater the level of organic matter degradation. The PC2 variables (TN., Amon Nit. and alkalinity) are related to the biological activity and determine the potency of the variables in relation to time. The greater the contribution of the variables related to organic degradation the greater the values in PC2 and the lesser the potency of these variables, whose influence is greater in the second stage of anaerobic degradation.

A sanitary landfill does not have a single age, but a variation of associated ages. These complex ecosystems converge toward the final stability of the organic matter, after countless transformations and biochemical interact tions between different microbial species, that can be modeled by means of chemometric analysis through the study of the physic-chemical parameters of the sanitary landfill. The method of multivariate analysis of the data (PCA) proved to be efficient to analyze and to characterize the leachate of the sanitary landfill.

The PC2 variables (TN., Amon Nit. and alkalinity) are related to the biological activity e quase totalidade do Amon Nit. in leached him it is originating from of the degradation of the matter orgânica. The effluent pouring out with significant amounts of nitrogen in a receiving body it can cause decomposition, decrease of the concentration of dissolved oxygen and toxicidade to the environment. It is recommended to accomplish treatment of removal of the ammonia from leachate before it discards it in the environment.

\section{Acknowledgements}

The authors thank the CNPQ, FAPERGS and University Caxias do Sul for financial support.

\section{REFERENCES}

[1] S. R. Qasin and W. Chiang, "Sanitary Landfill Leachate: Generation, Control and Treatment," Technomic Publishing Company, Lancaster, 1994.

[2] G. Andreotta and P. Cannas, "Chemical and Biological Characteristics of Landfill Leachte,” In: Landfilling of Waste: Leachate, 2nd Edition, Chapman and Hall Ltd, London, 1997, pp. 65-88.

[3] D. Augenstein and J. Pacey, "Modeling Landfill Methane Generation," Proceedings of 3rd International Landfill Symposium, Cagliari, 1991, pp. 115-148.

[4] L. F. Sá, "Evaporação Natural do Lixiviado do Aterro de Muribeca Através de um Destilado Solar. Master, Programa de Pós Graduação em Engenharia Civil, Centro Tecnologia e Geociências, Universidade do Pernambuco (UFPE), Recife, 2008.

[5] T. H. Christensen and R. Cossu, "Landfill Leachate: An Introduction,” In: Landfilling of Waste: Leachate, 2nd Edition, Chapman and Hall Ltd, London, 1997, pp. 3-13.

[6] J. M. Lema, R. Mendez and R. Blazquez, "Characteristics of Landfill Leachates and Alternatives for Their Treatment: A Review," Water, Air and Soil Pollution, Vol. 40, No. 3-4, 1988, pp. 223-250.

[7] P. Y. Jokela, R. H. Kettunen, K. M. Sormunen and J. A. Rintala, "Biological Nitrogen Removal from Municipal Landfill Leachate: Low-Cost Nitrification in Biofilters and Laboratory Scale in-Situ Denitrification,” Water Research, Vol. 36, No. 16, 2002, pp. 4079-4087. doi:10.1016/S0043-1354(02)00129-X

[8] P. Kjeldsen, M. A. Barlaz, A. P. Rooker, A. Bauna and T. H. Christensen, "Present and Long-Term Composition of MSW Landfill Leachate: A Review," Critical Reviews in Environmental Science and Technology, Vol. 32, No. 4, 
2002, pp. 297-336. doi:10.1080/10643380290813462

[9] M. Avella, E. Bonadies, E. Martuscelli and M. Rimedio, "European Current Standardization for Plastics Packaging Recoverable though Composting and Biodegradation," Polymer Testing, Vol. 20, No. 5, 2001, pp. 517-521. doi:10.1016/S0142-9418(00)00068-4

[10] CODECA, Companhia de Desenvolvimento de Caxias do Sul Relatório de Monitoramento Ambiental do Aterro Sanitário São Giácomo, Caxias do Sul, 2001.

[11] D. B. Voncina, D. Dobcnik, M. Novic and J. Zupan, "Chemometrics Characterization of the Quality of River Water,” Analytical Chimica Acta, Vol. 462, No. 1, 2002, pp. 87-100. doi:10.1016/S0003-2670(02)00298-2

[12] B. Walczak and D. L. Massart, "Dealing with Missing Data," Chemometrics and Intelligent Laboratory Systems, Vol. 58, No. 1, 2001, pp. 15-27. doi:10.1016/S0169-7439(01)00131-9

[13] M. P. Kallio, S.Mujunen, G. Hatzimihalis, P. Koutoufides, P. Minkkinen, P. Wilkie and M. Connor, "Multivariate Data Analysis of Key Polluants in Sewage Samples: A Case Study," Analytica Chimica Acta, Vol. 393, No. 1-3, 1999, pp. 181-191. doi:10.1016/S0003-2670(99)00287-1
[14] I. T. Jolliffe, “Principal Component Analysis,” SpringerVerlag, New York, 2002.

[15] K. Singh, A. Malik, V. K. Singh, D. Mohan and S. Sinha, "Chemometrics Analysis of Groundwater Data of Alluvial Aquifer of Gangetic Plain, North India," Analytica Chimica Acta, Vol. 550, No. 1-2, 2005, pp. 82-91. doi:10.1016/j.aca.2005.06.056

[16] M. Sena and R. Poppi, "Avaliação do uso de Métodos Quimiométricos em Análise de Solos," Química Nova, Vol. 23, No. 2000, pp. 547-556. doi:10.1590/S0100-40422000000400019

[17] C. Pérez, “Técnicas Estadísticas com SPSS,” Pearson Educacion, Madrid, 2001.

[18] J. E. Jackson, “A User Guide to Principal Components," John Wiley \& Sons, Inc., Hoboken, 2003.

[19] A. M. C. Grisa and M. Zeni, "Estudio de la Degradación de los Polímeros Commodities en el Medio Ambiente," Tese de Doutorado, León, 2004.

[20] D. Kulikowska and E. Klimiuk, "The Effect of Landfill Age on Municipal Leachate Composition,” Bioresource Technology, Vol. 99, No. 13, 2008, pp. 5981-5985. doi:10.1016/j.biortech.2007.10.015 